DOI: https://doi.org/10.24867/09CG03Lazarevic

\title{
HIDRAULIČKA ANALIZA ODVOĐENJA UPOTREBLJENIH VODA NASELJA MALI IĐOŠ SA MAGISTRALNIM KOLEKTOROM MALI IĐOŠ-FEKETIĆ-PPOV
}

\section{HYDRAULIC ANALYSIS OF WASTEWATER DISCHARGE FROM THE SETTLEMENT MALI IĐOŠ WITH MAIN COLLECTOR MALI IĐOŠ-FEKETIĆ-WWTP}

Tijana Lazarević, Matija Stipić, Fakultet tehničkih nauka, Novi Sad

\begin{abstract}
Oblast - GRAĐEVINARSTVO
Kratak sadržaj - U radu je izloženo rešenje odvođenja otpadnih voda naselja Mali Iđoš, Lovćenac i Feketić do postrojenja za prečišćavanje otpadnih voda. Radi se o primeru kanalizacionog sistema gde se zbog topografije terena javljaju velike dubine ukopavanja cevi i potreba za ugradnjom crpnih stanica. Glavni kolektor je projektovan za prihvatanje otpadnih voda iz sva tri naselja. Modeliranje mreže $i$ hidraulički proračun su urađeni pomoću programskog paketa SWMM.
\end{abstract}

Ključne reči- hidraulička analiza, otpadne vode, glavni kolektor, prečistač otpadnih voda

Abstract - The paper presents the solution of wastewater disposal in the settlements of Mali Iđoš, Lovćenac and Feketic to the sewage treatment. This is an example of a sewage system where due to topography of the terrain, large depths of pipe burial occur and therefore pumping stations are needed to be installed. The main collector is designed to accept sewage from all three settlements.

Network modeling and hydraulic calculation were done by using the SWMM software package.

Keywords- hydraulic analysis, wastewater, main collector, sewagw treatment

\section{UVOD}

Svega $33 \%$ područja AP Vojvodine pokriveno je kanalizacionom mrežom, gde veliki deo izgrađene kanalizacione mreže nema prečistač otpadne vode, pa se sva otpadna voda izliva direktno u vodotok i zagađuje ga.

$\mathrm{Na}$ teritoriji opštine Mali Iđoš ne postoji izgrađena kanalizaciona mreža, osim u centralnim delovima naselja, gde je priključena nekolicina objekata. Upotrebljene vode se uglavnom ispuštaju u bivše kopane bunare ili nepropisno izvedene septičke jame. $\mathrm{Na}$ ovaj način, direktno se ugrožava kvalitet podzemnih voda i zivotna sredina uopšte.

Cilj ovog rada je povećati higijenu i kvalitet života $u$ opštini Mali Iđoš, ali i u samom recipijentu, tako što će stare septičke jame biti sanirane i izbačene iz upotrebe, a potom da se izgradi kanalizaciona mreža od PVC cevi koja će odvoditi otpadne vode do projektovanog postrojenja za prečisćavanje otpadnih voda.

\section{NAPOMENA:}

Ovaj rad proistekao je iz master rada čiji mentor je bio doc. dr Matija Stipić

\section{OPŠTE KARAKTERISTIKE PREDMETNOG PODRUČJA}

Opština Mali Iđoš se nalazi u severno-Bačkom okrugu. U sastavu opštine se nalaze tri naselja: Mali Iđoš, Lovćenac i Feketić. Prema popisu iz 2011. godine u opštini Mali Iđoš ima 12.031 stanovnika.

Ukupna površina građevinskog reona Opštine iznosi 1407.82 ha, od čega $60 \%$ predstavljaju površine za stanovanje.

Analizom demografskog razvoja Opštine uočeno je da populaciona veličina ima trend paramentalnog pada broja stanovnika. Prema poslednjem popisu stanovništva, u Opštini Mali Iđoš je zabeležena depopulacija u svim selima i opštinama.

Ovakve tendencije posledica su raslojavanja porodica, konstantnog pada nataliteta i pogoršanje starosne strukture populacije Opštine. Do povećanja broja stanovnika moguće je doći konkretnim promenama $u$ svim naseljima, te podizanjem njihovih standarda.

\section{MERODAVNE KOLIČINE OTPADNIH VODA}

Otpadne vode se dele na:

- Upotrebljene vode iz domaćinstva

- Upotrebljene vode iz industrije

- Atmosferske vode

- Komunalne vode

Zadatak kanalizacione mreže naselja je pre svega odvođenje otpadnih voda iz naselja, odnosno industrije, do postrojenja za prečišćavanje otpadnih voda (PPOV).

Odabir sistema kanalisanje (načina evakuacije otpadnih voda) zavisi od niza faktora: broja stanovnika, topografskih karakteristika, sanitarnih zahteva, tehničkoekonomskih pokazatelja i sl.

U slučaju opštine Mali Iđoš definisan je separativni sistem kanalisanja naselja, gde se atmosferske i čiste industrijske upotrebljene vode odvode jednom mrežom kanala, a domaće $\mathrm{i}$ industrijske upotrebljene vode odvode drugim sistemom kanala.

Što se tiče kanalisanja upotrebljenih voda postoje dva osnovna načina: sa gravitacionim tečenjem i pod pritiskom. U ovom radu se razrađuje rešenje kanalizacije sa gravitacionim tečenjem., čije su karakteristike: velike dubine ukopavanja, veliki prečnici cevi, značajna ulaganja, lako održavanje i sigurnost rada nezavisno od električne energije. 


\section{MERODAVNI PRORAČUNSKI PARAMETRI I IZBOR CEVNOG MATERIJALA}

Cevni materijal za izgradnju kanalizacije upotrebljenih voda mora zadovoljiti niz zahteva, od kojih su najvažniji trajnost, čvrstoća i vodonepropusnost. Nepropusnost materijala za vodu se pokazuje odsustvom proceđivanja vode iz zemljišta u kanalizaciju i obrnuto. Koje cevi će biti primenjene zavisi od tržišnih uslova prilikom izgradnje objekta. Kod opredeljenja treba imati u vidu da kanalizacija predstavlja objekat koji se gradi za potrebe narednih 30-50 godina. Kao najpogodnije pokazale su se PVC cevi, jer je veoma lak materijal, jednostavan za transport, jeftin, otporan na koroziju, vek trajanja duži od 50 godina $\mathrm{i} \mathrm{dr}$.

Maksimalna brzina tečenja otpadne vode u kanalizacionoj mreži se propisuje kako bi se sprečila erozija, te habanje i oštećenje objekta usled prevelike brzine.

Minimalne brzine tečenja otpadne vode su one brzine pri kojima ne dolazi do istaložavanja suspendovanih materija u kanalizacionoj mreži i do začepljenja iste.

Najmanja brzina strujanja treba da bude $0,4 \mathrm{~m} / \mathrm{s}$ pri dubini punjenja kanala $2-3 \mathrm{~cm}$, ili $0,8 \mathrm{~m} / \mathrm{s}$ kada je kanal pun do vrha. Smatra se da su ove brzine dovoljne da se čvrste čestice održe u suspenziji. Najveće brzine su ograničene na $3 \mathrm{~m} / \mathrm{s}$ u punom profilu.

Minimalni podužni padovi predstavljaju onaj nagib, koji pri gravitacionom tečenju obezbeđuje potrebnu energiju za vučenje nanosa odnosno, koji sprečava istaložavanje materijala. U radu su usvojeni minimalni padovi $2.5 \%$.

Minimalni prečnici cevi predstavljaju tehničko-ekonomsku kategoriju. Minimalne prečnike cevi treba ograničiti, bez obzira na ispunjenost profila i minimalnu brzinu, u cilju sprečavanja začepljenja i olakšanog prečišćavanja kanalizacionog kolektora. U radu su usvojeni minimalni prečnici $250 \mathrm{~mm}$.

\section{MODELIRANJE TEČENJA U KANALIZACIONIM SISTEMIMA}

$\mathrm{U}$ radu je prikazana jedna mogućnost matematičkog modeliranja, odnosno računarske simulacije tečenja vode u kanalizacionom sistemu. Kod ovih sistema promena dotoka je spora, pa neustaljenost tečenja nije izražena $\mathrm{i}$ može se zanemariti.

Tečenje otpadnih voda je gravitaciono i obično se opisuje jednačinama održanja mase i količine kretanja za linijsko tečenje vode u otvorenom kanalu (tzv. Sen-Venanove jednačine) [2].

$$
\begin{gathered}
\frac{\partial \mathrm{A}}{\partial t}+\frac{\partial Q}{\partial x}=0 \\
\frac{\partial Q}{\partial t}+\frac{\partial}{\partial x}\left(\beta \frac{Q^{2}}{A}\right)+g A \frac{\partial z}{\partial x}+g A S_{f}=0
\end{gathered}
$$

U mirnom režimu tečenja potreban je po jedan uslov na uzvodnom i nizvodnom kraju (nivo, proticaj ili kriva protoka), a u burnom režimu po dva granična uslova na uzvodnom i nizvodnom kraju.

Izostavljanje pojedinih članova, u gore pomenutim jednačinama, omogućava jednostavnije i efikasnije numeričko rešenje, ali se time gubi na tačnosti dobijenog rešenja.
Za rešavanje Sen-Venanovih jednačina softver koristi ti modela:

- Model ustaljenog tečenja

- Model kinematskog talasa

- Model dinamičkog talasa

U radu je korišćen model dinamičkog talasa, koji rešava kompletne Sen-Venanove jednačine i na taj način daje najpreciznije rešenje.

\section{PROGRAMSKI PAKET EPASWMM 5.0.}

SWMM je nastao 1970. godine i koristi se za planiranje, analizu i projektovanje odvođenja atmosferskih voda, kombinovanih kanalizacionih sistema, fekalnih kanalizacionih sistema kolektora i ostalih sistema atmosferske kanalizacije.

Primenom ovog softverskog paketa u projektovanju kanalizacije za upotrebljenu vodu, omogućuje se kompleksno sagledavanje situacije na terenu uzimajući u obzir raspored i karakteristike urbanizovanih površina, raspored korisnika, hidrološke podatke o kišama i oticajima, tečenje vode po površini terena i u kanalizacionoj mreži.

\subsection{Mogućnosti programa}

SWMM sadrži mnogobrojne fleksibilne hidrauličke mogućnosti i modelovanja koja se koriste za usmeravanje atmosferske vode, fekalne otpadne vode i spoljašnjih dotoka kroz drenažnu mrežu cevi, kanala, pogona za čuvanje/tretiranje i obilaznih struktura.

Tu spadaju i sledeće mogućnosti:

- Rad sa mrežama neograničene veličine

- Korišćenje raznih standardnih oblika otvorenih i zatvorenih kanala, kao i prirodnih kanala

- Modelovanje posebnih elemenata, kao što su jednačine za čuvanje/tretman razdelnica toka, pumpe, prelivi i prigušnice

- Korišćenje spoljašnjih protoka i unetih podataka o kvalitetu vode iz površinskih voda, podzemnog međudotoka, direktnog oticaja, sanitarnog protoka po suvom vremenu i dotoka koji odredi korisnik

- Primena metoda usmeravanja protoka pomoću kinematskog ili dinamičkog talasa

- Modelovanje raznih režima protoka, kao što su povratna vodena masa, preopterećenje, obrnut protok i visina krune preliva

Prilikom dimenzionisanja kanalizacione mreže naselja Mali Iđoš, Lovćenac i Feketić, ulazni parametri koji određuju tok proračuna moraju biti unešeni.

U ulazne parametre spadaju:

- Broj stanovnika

- Analizirani (projektni) period

- Potrošnja, odnosno količina upotreblje vode naselja, industrije, javnih objekata, infiltracije, strane vode

- Vrsta industrije

- Koeficijent neravnomernosti stanovništa, industrije $\mathrm{i}$ javnih objekata

- Tip i prečnik usvojenih cevi

- Dubina polaganja cevi uz uslov poštovanja minimalnih i maksimalnih ograničenja

- Nagib cevi 


\section{HIDRAULIČKI PRORAČUN}

Hidraulički proračun rađen je za svako naselje ponaosob. U zavisnosti od dijagrama časovne neravnomernosti koji su usvojeni za predmetna naselja i predstavljaju neravnomernost potrošnje otpadne vode, pa samim tim i neravnomernost oticanja iz naselja znatno se razlikuje u određenim delovima dana [3].

Hidrauličkom proračunu prethodila je obrada podloga, odnosno priprema ulaznih podataka za simulaciju tečenja u sistemu kolektora.

Usvojena specifična dnevna potrošnja vode po stanovniku na dan $\mathrm{q}_{\text {spec }}=1301 / \mathrm{st} / \mathrm{dan}[4]$.

$$
Q_{s r, d n}=q_{\text {spec }} * N
$$

$\mathrm{N}-$ ukupan broj stanovnika

$$
Q_{\max , d n}=Q_{s r, d n} * k_{d}
$$

$\mathrm{K}_{\mathrm{d}}$ - koef.dnevne neravnomernosti

Korišćeni softverski paket omogućava proračun neustaljenog tečenja u cevovodima i simulaciju dnevnog protoka (24 sata), izačunate količine srednjeg dnevnog protoka deonica su množene sa koeficijentima časovnih neravnomernosti $\mathrm{k}_{\mathrm{h}}$ [4].

Dijagrami časovne neravnomernosti za naselja Mali Iđoš, Lovćenac i Feketić su uneta u hidraulički proračun programskog paketa SWMM.

$$
Q_{\max , h}=Q_{s r, d n} * k_{h}
$$

Specifična deonična količina otpadnih voda:

$$
Q_{\text {spec,deon }}=\frac{Q_{\text {max }, \text { dn }, u k u p}}{\Sigma L}
$$

$\Sigma \mathrm{L}$ - ukupna dužina kanalizacione mreže

Čvorno opterećenje:

$$
Q_{c v o r, i}=Q_{\text {spec,deon }} * \Sigma L_{i}
$$

$\Sigma \mathrm{L}_{\mathrm{i}}$-nizvodna deonica od čvora

Čvorno opterećenje zadato je u svakom čvoru hidrauličkog modela kao bazna potrošnja.

Na Slici 1. imamo prikazan izgled modela kanalizacione mreže naselja Mali Iđoš, na osnovu kog se vrši simulacija tečenja u kanalizacionom sistemu.

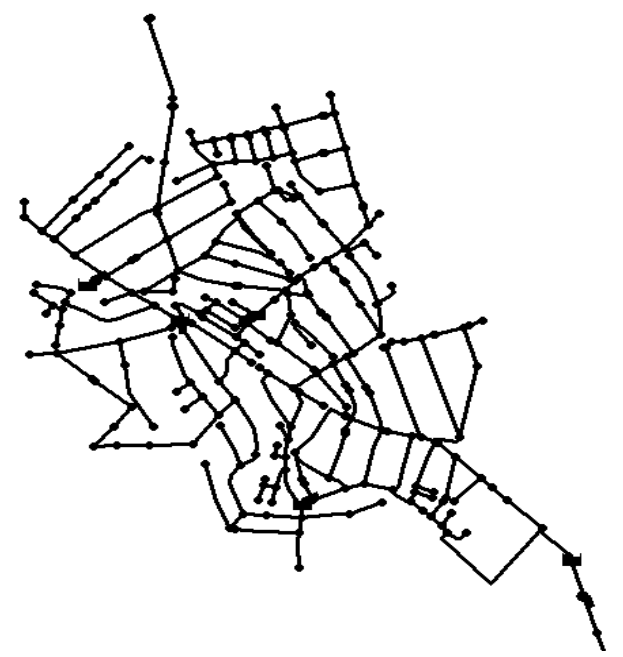

Slika 1. Izgled modela kanalizacione mreže naselja Mali Iđoš
Nakon puštanja simulacije u rad, dobijamo tabelarni prikaz brzina, proticaja i ispunjenosti u svakom času vremena trajanja simulacije.

\section{CRPNE STANICE}

Budući da otpadna voda otiče kanalizacionom mrežom gravitaciono, na pojedinim mestima da ne bi došlo do prevelikog ukopavanja kanalizacionih cevi, rade se crpne stanice.

Crpne stanice zahtevaju permanentne eksploatacione troškove i predstavljaju potencijalnu opasnost za funkcionisanje mreže u slučaju prekida u napajanju pogonskom energijom za hidromašinsku opremu, zbog toga se broj ovih objekata nastoji svesti na minimum [1].

Osnovni delovi crpnih stanica su: crpni bazen, pumpe i potisni cevovod.

Crpni bazen je prostor koji služi za zadržavanje vode koja dolazi iz uzvodnog dela kanalizacionog sistema. Veličina tog prostora zavisi od režima rada pumpi i karakteristika dotoka [1].

Minimalna zapremina crpnog bazena računa se po sledećoj formuli:

$$
V_{\text {min }}=\frac{\left(t_{s}+t_{r}\right)+Q_{\max , h}}{4}=0.09 * Q(8)
$$

$\mathrm{t}_{\mathrm{s}-\text { vreme stajanja pumpe }}$

$\mathrm{t}_{\mathrm{r}}$ - vreme rada pumpe

$\mathrm{Q}_{\max , \mathrm{h}}$ - maksimalni časovni dotok otpadne vode

Pumpe su hidraulučke mašine koje daju energiju fluidu, koristeći mehanički rad pogonske mašine. U kanalizaciji se najčešće koriste centrifugalne pumpe koje imaju šire prolaze u radnom kolu i kućištu, što doprinosi sprečavanju začepljenja pumpe sadržajima iz otpadne vode. U ovom radu korišćene su Flygt pumpe, odabrane uz pomoć programa za odabir pumpe, xylect.

Potisni cevovod služi za prebacivanje otpadne vode iz crpne stanice do mesta prepumpavanja.

Na kanalizacionoj mreži naselja Mali Iđoš, Lovćenac i Feketić nalazi se šest crpnih stanica, od toga četiri crpne stanice u naselju Mali Iđoš, jedna na magistralnom kolektoru u naselju Lovćenac i jedna na magistralnom kolektoru u naselju Feketić.

\section{PPOV-POSTROJENJE ZA PREČIŠĆAVANJE OTPADNIH VODA}

Lokacija uređaja za prečišćavanje otpadnih voda planira se na desnoj obali reke Krivaje, ispod Feketića na površini od 2.5 ha.

Otpadne vode naselja prikupljaju se i odvode separativnim sistemom kanalizacije. U javnu kanalizacionu mrežu može se ispustiti samo prethodno tretirana industrijska voda, čiji kvalitet mora odgovarati kvalitetu otpadnih voda iz domaćinstva, te je kompletna industrija u obavezi da uradi primarno prečišćavanje kako bi se postigao traženi kvalitet.

Prečišćavanje otpadnih voda predviđa primenu mehaničko-biološkog postupka.

Mehaničko prečišćavanje obuhvata filtraciju kroz grubu rešetku, odvajanje peska putem gravitacionog taloženja i simultanu redukciju sadržaja masnoće. 
Biološko prečišćavanje se zasniva na postupku sa aktivnim muljem (SBR) sa nitrifikacijom, uklanjanjem fosfora $\mathrm{i}$ istovremenom stabilizacijom mulja.

Primena "SBR postupka" ima prednost jer se u jednom rezervoaru mogu obavljati svi postupci biološke obrade, uključujući odvod bistre vode [5].

Sve prikupljene otpadne vode koje dolaze na PPOV se prečišćavaju i ispuštaju preko jednog cevovoda u reku Krivaju.

\section{ZAKLJUČAK}

Cilj ovog rada jeste poboljšanje životnog standarda naselja Mali Iđoš, Lovćenac i Feketić, poboljšanje kvaliteta podzemnih voda i životne sredine, a to se u velikoj meri može postići izgradnjom kanalizacione mreže.

$\mathrm{Na}$ osnovu raspoloživih podloga i podataka o stanovništvu, projektovana je gravitaciona kanalizacija. Kanalizaciona mreža je formirana tako da se sva sakupljena otpadna voda sa teritorije Mali Iđoš, Lovćenac i Feketić odvodi zajedničkim magistralnim kolektorom do postrojenja za prečišćavanje otpadnih voda, koji se nalazi u Feketiću.

Za izgradnju kanalizacione mreže fekalnih voda usvojene su cevi od tvrdog polivinil hlorida (PVC) zbog niza prednosti i povoljnih karakteristika materijala. Najmanji usvojeni prečnici cevi su $250 \mathrm{~mm}$ na sekundarnoj kanalizacionoj mreži, a najveći prečnici su od $600 \mathrm{~mm}$ na magistralnom kolektoru.

Hidraulički proračun i dimenzionisanje kanalizacione mreže urađeni su za merodavnu količinu otpadne vode, a celokupan hidraulički proračun je urađen u softverskom paketu EPA SWMM.

U naselju Mali Iđoš, Lovćenac i Feketić postoji šest crpnih stanica, koje potiskuju otpadnu vodu do jednog zajedničkog postrojenja za prečišćavanje otpadne vode. Za prečišćavanje fekalne vode primenjuje se mehaničkobiološki postupak, uz posebnu obradu mulja tzv. SBR postupak.
U radu su dimenzionisani osnovni objekti kanalizacione mreže.

Problemi odvođenja otpadne vode iz opštine Mali Iđoš se rešavaju izgradnjom kanalizacionih sistema, koji se projektuju sa ciljem da ispune zadatak za šta cu predviđeni, uz što manje troškove izgradnje.

\section{LITERATURA}

[1] Pisana predavanja: doc. dr Matija Stipić, Komunalna hidrotehnika, Fakultet tehničkih nauka u Novom Sadu, 2016

[2] Hajdin Georgije: Mehanika fluida knjiga prva Uvođenje u hidrauliku, Građevinski fakultet, Beograd, 2002

[3] Milojević Miloje, Snabdevanje vodom i kanalisanje naselja, naučna knjiga, Beograd, 1987

[4] German rules and standards- STANDARD ATVDVWK-A 134E

[5] Dr Dejan Ljubisavljević, Prečišćavanje otpadnih voda, Građevinski fakultet, Beograd, 2004

\section{Kratka biografija:}

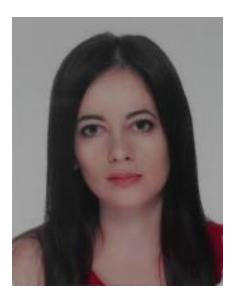

Tijana Lazarević rođena je u Vlasenici 1991. godine. Diplomirala je na građevinskom odseku Fakulteta tehničkih nauka u Novom Sadu 2016. godine na smeru Hidrotehnika. Master rad na Fakultetu tehničkih nauka iz oblasti komunalne hidrotehnike - hidraulička analiza odvođenja upotrebljenih voda odbranila je 2020. godine. 